\title{
Llantas usadas: materia prima para pavimentos y múltiples ecoaplicaciones ${ }^{1}$
}

Fecha de recepción: 29 de octubre de 2017

Fecha de aprobación: 15 de diciembre de 2017

\author{
Leidy Viviana Patiño ${ }^{2}$ \\ Universidad Piloto de Colombia \\ leidy-patino@unipiloto.edu.co \\ María Aleyda Rodríguez Ramos ${ }^{3}$ \\ Universidad Piloto de Colombia \\ rodriguez2@unipiloto.edu.co
}

DOI: https://doi.org/10.21158/23823399.v5.n0.2017.2004

Cómo citar este artículo/ To reference this article/Comment citer cet article/ Para citar este artigo: Patiño, L. V. y Rodríguez Ramos, M. A.). Llantas usadas: materia prima para pavimentos y múltiples ecoaplicaciones. Revista Ontare. 5, p 73 - 114.

\section{Resumen}

El propósito de este estudio es realizar análisis reflexivo por metodología de revisión documental, respecto a la problemática de la contaminación ambiental derivada de la inadecuada disposición de llantas usadas en la ciudad de Bogotá, y de cómo mediante procesos de reciclaje y recuperación como la trituración mecánica de las mismas, se pueden obtener subproductos entre otros, el granulado de caucho reciclado, el cual tiene aplicaciones y usos por explorar. Lo anterior con el objetivo de determinar la viabilidad y factibilidad de comercializar grano de caucho reciclado como materia prima para la producción de mezcla asfáltica modificada empleada para la pavimentación vial.

\section{Palabras clave}

Llantas usadas; trituración mecánica; granulo de caucho reciclado; mezcla asfáltica modificada; contaminación ambiental.

\footnotetext{
1 Articulo derivado del proyecto de investigación del mismo nombre: «Llantas usadas materia prima para pavimentos y múltiples eco-» por la Facultad de administración de empresas de la Universidad Piloto de Colombia, vigencia 20167.

2 Estudiante del Programa de Administración de Empresas, de la Universidad Piloto de Colombia.

3 Estudiante del Programa de Administración de Empresas, de la Universidad Piloto de Colombia.
} 


\title{
Used tires: raw material for road paving and multiple eco-applications
}

\begin{abstract}
The purpose of this study is to perform a reflexive analysis by means of documentary review methodology, regarding the problem of environmental pollution derived from the inadequate disposal of used tires in the city of Bogotá, and how how subproducts like the recycled tire crumb, among others, which has applications and uses to be explored, can be obtained through recycling and recovery processes such as the mechanical crushing. The foregoing with the objective of determining the viability and feasibility of marketing recycled rubber grain as raw material for the production of the modified asphalt mix that is used for road paving.
\end{abstract}

\section{Keywords}

Used tires; mechanical crushing; recycled tire crumb; modified asphalt mix; environmental pollution.

\section{Pneus usés: matières premières pour sols et autres éco-applications.}

\section{Résumé}

Le but de cette étude est d'effectuer une analyse réflexive basée sur une méthodologie documentée dont le sujet traite du problème de la pollution environnementale dérivée de l'élimination inadéquate des pneus usés dans la ville de Bogotá et de la manière dont les processus de recyclage et de récupération comme le broyage mécanique permettent l'obtention de sous-produits tels que les granulés de caoutchouc recyclés permettant des applications et utilisations encore non explorées. Nous tenterons ensuite de déterminer la viabilité et la faisabilité de la commercialisation du grain de caoutchouc recyclé en matière première pour la production d'asphalte modifié et utilisé pour le pavage des routes.

\section{Mots clefs}

Pneus usés; broyage mécanique; granulés de caoutchouc recyclé; mélange d'asphalte modifié; contamination environnementale. 


\section{Pneus de carros usados: \\ como matéria prima para pavimentos \\ e múltiplos eco-aplicativos}

\section{Resumo}

O propósito deste estudo é realizar análise reflexiva por metodologia de revisão documentária, a respeito da problemática da contaminação ambiental derivada da inadequada disposição de pneus de carros usados na cidade de Bogotá, e de como mediante processos de reciclagem e recuperação como a trituração mecânica das mesmas, podem ser obtidos subprodutos, entre outros, o granulado de borracha reciclada, que tem aplicações e usos por explorar. Tudo isto com o objetivo de determinar a viabilidade e factibilidade de comercializar granulado de borracha reciclada como matéria prima para a produção de mistura asfáltica modificada, empregada para a pavimentação de vias.

\section{Palavras-chave}

Aros usados; trituração mecânica; granulado de borracha reciclad; mistura asfáltica modificada; contaminação ambiental. 


\section{Introducción}

T a necesidad de desplazarse y facilitar sus tareas diarias motivó al Chombre a la invención de la rueda. Las ruedas se construyeron en el inicio de piedra, madera y metal y, finalmente, fueron revestidas de caucho, en busca de mejorar su eficacia. Así, nacieron los neumáticos, también denominados llantas.

La explotación del caucho, principal componente de las llantas, data de 1789. Fueron los indígenas de la selva amazónica quienes hallaron las propiedades del «árbol que llora».

Más tarde, la empresa estadounidense Goodyear descubrió en 1839 la vulcanización del caucho, hallazgo que años después condujo al escoces John Boyd Dunlop a la invención del primer neumático, que consistía en una «cámara de aire» envuelta en una tela de algodón tejido, pegada y clavada en un aro de madera.

Sin embargo, en contraposición a los beneficios que trajo la invención de la llanta a la humanidad y el promisorio futuro que según los expertos tiene la industria productora de neumáticos en Colombia, un sector en crecimiento impulsado por el aumento de la industria automotriz, se encuentra la problemática que trae consigo el desecho inadecuado de las llantas. Esta situación que agudiza la contaminación ambiental, uno de los más grandes problemas del mundo de hoy.

Se ha identificado que las llantas usadas que son desechadas constituyen un grave problema debido a que, según se estima, una llanta tarda en degradarse alrededor de cien años. Muchas de estas llantas contienen sustancias que suelen ser peligrosas y llegan a causar grandes problemas especialmente en el ambiente y en la salud si se desechan al aire libre o en sitios de disposición sin controles. 
La quema de llantas produce impactos diversos tanto para la salud pública por los compuestos que contiene como para el medio ambiente. Se han encontrado 38 compuestos dañinos emitidos al aire debido a la mezcla de gases, metales, hidrocarburos y vapores orgánicos. Se ha demostrado que esas emisiones son tóxicas. Estos contaminantes producen cáncer, malformaciones congénitas, generan problemas en los pulmones, entre otros desórdenes de salud. (Secretaría Distrital de Ambiente, s. f.)

Esta situación no solo arruina paisajes, sino que también ocasiona graves daños en los ecosistemas, ya que, cuando las llantas se desechan al aire libre, acumulan fácilmente agua que se estanca, basura y otros desechos, que se convierten en focos de infecciones, hervideros de mosquitos portadores de enfermedades como malaria, dengue, paludismo, roedores y plagas.

Existen actualmente una amplia variedad de alternativas para disminuir estos impactos ambientales negativos mediante el aprovechamiento de los subproductos de las llantas en desuso, compuestas por acero (15 $\%$ ), fibras (5\%) y caucho ( $80 \%)$; la recuperación de este último material parece constituir un mercado con amplias oportunidades de negocios, entre ellas, la producción de una mezcla asfáltica modificada con gránulo de caucho reciclado (GRC), a partir del proceso de trituración de llantas de caucho. Teniendo en cuenta lo anterior, el objeto de este trabajo es proponer los lineamientos básicos que debe tener en cuenta una empresa que utilice llantas usadas con el fin de obtener materia prima para la elaboración de pavimento asfáltico, mediante el análisis del mercado con el propósito de establecer los clientes potenciales que este dicho material en Colombia. 


\section{La necesidad de movilidad: la rueda}

esde la Antigüedad, movilizarse ha sido una necesidad primordial en la vida del hombre. Para desplazarse y transportar sus bienes, ideó la rueda, uno de los artefactos de tecnología de mayor impacto y relevancia en el desarrollo de las sociedades y del comercio. La evolución de la rueda marcó el nacimiento de diversas máquinas y gran número de medios de transporte terrestre que van desde los más primarios, como bicicletas, motocicletas, a los automóviles y otros vehículos de mayores capacidades.

\section{El caucho y las llantas}

A $\mathrm{n}$ el transcurso de este proceso, los indígenas de la selva amazónica Cencontraron en el cautchuc, «árbol que llora», el así denominado árbol del caucho, las increíbles propiedades de una sabia, capaz ser estirada hasta ocho veces su longitud normal sin romperse, para luego volver a su posición inicial. La explotación intensiva del caucho data de 1789 y están ligadas a la demanda de este material por países europeos como Francia y el Reino Unido y de los Estados Unidos relacionados con el avance tecnológico y crecimiento de la industria del transporte, presionados por la necesidad de desplazamientos rápidos de personas y mercancías. Más tarde, en 1839, el estadounidense Charles Goodyear, descubriría la vulcanización, proceso en el que caucho crudo es calentado en presencia de azufre, que lo hace más duro y resistente al frío (Clickmica, s.f). Esta condujo a la rueda encauchada y dio paso a la llanta con cámara de aire, inventada en 1887 por el escocés John Boyd Dunlop, además, se introdujo el motor a combustión y el asfalto (Sierra, 2011). 
En 1891, los hermanos André y Édouard Michelin inventan el neumático desmontable, lo cual permitió su aplicación en la industria y el deporte. Hacia 1915, los alemanes pusieron a punto el caucho sintético (El Comercio, 2012), a partir de esto se estimula el cultivo y explotación del caucho y la fabricación de productos desde este material. El descubrimiento del caucho y la invención de la llanta o neumático revolucionaron la movilidad del hombre y las industrias de transporte terrestre, automotriz, auto y motopartes, entre otras.

\section{EI mercado de las llantas nuevas}

71 comportamiento del mercado de las llantas ha cambiado en 1 Colombia. Tradicionalmente, al aumentar la venta de vehículos, se espera que crezca la venta de llantas. En 2016, esto no ocurrió así: mientras el comercio de vehículos registró una caída del $15 \%$, las importaciones de llantas crecieron un 16,43 \% (Fenalco, s. f.). Esto alienta a los empresarios afectados por la devaluación, de las llantas en su mayoría importadas; así mismo, las empresas mejoraron sus balances debido a sus estrategias agresivas de negocios, donde buscaban convertirse en productoras directas para las ensambladoras; y por último, a la tendencia fuerte, a la demanda creciente de llantas de este segmento económico provenientes de China, la India y Corea (Tabla 1).

Tabla 1. Generación de llantas en Colombia por región

\begin{tabular}{|l|c|c|}
\hline Región & Porcentaje & Toneladas de llantas \\
\hline Cundinamarca & 28,22 & 53760 \\
\hline Antioquia & 18,31 & 34881 \\
\hline Eje Cafetero & 6,78 & 12916 \\
\hline Costa Atlántica & 13,72 & 26137 \\
\hline Valle & 17,27 & 32900 \\
\hline Otras regiones & 15,70 & 29909 \\
\hline
\end{tabular}

Fuente. Ministerio de Medio Ambiente y Desarrollo Sostenible, 2017. 
El desafío del mercado de las llantas en Colombia es crecer, para cubrir con un parque automotor calculado en 12,5 millones de vehículos al cierre de 2016, donde las ventas de llantas en el país para el mismo periodo estuvieron cerca de los 10 millones de unidades. En términos de valor, se estima que las ventas del sector estuvieron alrededor de COP 1,5 billones, de acuerdo con cifras de la industria.

Aunque la anterior cifra suene elevada, se encuentra por debajo de los estándares internacionales; por un lado, el índice de motorización en Colombia es de los más bajos de América Latina y del mundo: un vehículo por cada doce ciudadanos, esto sumado al mal estado de las carreteras, la falta de infraestructura vial de calidad que les impide hacer menos viajes, el elevado costo de los peajes y las cargas de combustible que deben asumir los propietarios (Dinero, 2017)

En consecuencia, a mayor compra de llantas nuevas de línea económica, nuevas estrategias de ventas, y el crecimiento del parque automotor a nivel nacional intensificará el desecho de las llantas antiguas, teniendo el propietario la posibilidad de cambiarlas a precios más bajos y en un periodo más corto, lo que aumentará las frecuencias de compra y desecho de llantas.

\section{Adecuada e inadecuada disposición de llantas usadas y residuos especiales}

\footnotetext{
Tos residuos sólidos que necesitan un tratamiento especial, o Ubien porque se consideran peligrosos, o bien porque pueden ser aprovechados como nuevos insumos, son tratados en el país en programas de posconsumo; de esos materiales hacen parte productos cotidianos como llantas, pilas, plaguicidas, tecnológicos, medicamentos, bombillas y baterías (El Tiempo, 2016b).
} 
Las llantas usadas no son consideradas en Colombia como un residuo peligroso, pero, debido a su volumen, la dificultad que representa su degradación en el tiempo y la potencialidad que tienen los elementos que las constituyen para ser aprovechados nuevamente se catalogan como residuos especiales y requieren un manejo diferenciado al de los demás residuos (Dinero, 2017).

Las llantas requieren ser devueltas a los productores para favorecer el reciclaje, el aprovechamiento, así como evitar su inadecuada disposición (Ministerio de Medio Ambiente y Desarrollo Sostenible, 2017).

El sistema de acopio de llantas usadas colombiano incluye las llantas de vehículos - carros, camiones, buses, camionetas, entre otros - con un rin menor o igual a 22,5 . No se incluyen las llantas de motocicletas, bicicletas, vehículos fuera de carretera o de rin superior a 22,5 (Ministerio de Medio Ambiente y Desarrollo Sostenible, 2017).

Los establecimientos que pertenecen a los sistemas de recolección de llantas usadas deben cumplir con requisitos técnicos y de seguridad para asegurar que los residuos son manejados de forma segura y adecuada. Los sitios adecuados se caracterizan por tener medidas de seguridad frente a incendios, almacenar las llantas de forma ordenada, en sitios cubiertos —no a la intemperie - , disponer de publicidad visible y documentación que haga alusión a los sistemas y sus responsables (Ministerio de Medio Ambiente y Desarrollo Sostenible, 2017).

Los sitios o personas no autorizadas para recolectar llantas pueden identificarse principalmente porque apilan las llantas en sitios descubiertos, no disponen de medidas de seguridad frente a incendios, ni de publicidad o material alusivo al Sistema de Recolección Selectiva y Gestión Ambiental de Llantas Usadas. Para entregar las llantas usadas, se debe tener en cuenta que, una vez las llantas deben ser reemplazadas, o se tenga alguna que deba ser desechada, verificar dentro del listado de sistemas presentados, y de 
acuerdo con la marca comercial o con el proveedor de confianza, un establecimiento que disponga de un punto de recolección autorizado. Una vez en el sitio, hacer entrega de la llanta usada o permitir que un técnico, operario o empleado se la lleve al sitio de almacenamiento ubicado en el establecimiento (Ministerio de Medio Ambiente y Desarrollo Sostenible, 2017).

\section{Sistema sostenible de recolección selectiva y gestión ambiental de llantas usadas}

Dara hacerle frente al grave problema medioambiental que genera la inadecuada disposición de llantas usadas, el Ministerio de Medio Ambiente y Desarrollo Sostenible, junto con la Asociación Nacional de Empresarios de Colombia (ANDI), crearon en 2009 un proyecto que unió a 52 empresas colombianas ensambladoras e importadoras de carros y los fabricantes e importadores de llantas de todo el país bajo un sistema de masiva recolección selectiva de llantas usadas. El proyecto comenzó con un programa piloto que se llevó a cabo en Medellín, que consistía en recoger, en 20 estaciones de servicio seleccionadas, las llantas usadas y llevarlas a una planta de trituración donde se les realizó un proceso de reciclado que no contamina el medio ambiente. Este proceso consistía en la trituración y separación de los materiales de la llanta para que luego sean utilizados como materia prima en otros procesos. Tras obtener excelentes resultados, de acuerdo con el Comité Posconsumo de Llantas Usadas de la ANDI, desde agosto de 2010 hasta marzo de 2011, se han recogido 27500 neumáticos, es decir, 375 t, en las estaciones habilitadas para el programa (vida+verde, s. f.). 
Además, el Ministerio de Medio Ambiente y Desarrollo Sostenible emitió la Resolución 1457/2010, de 29 de julio, por la cual se establecen los sistemas de recolección selectiva y gestión ambiental de llantas usadas y se adoptan otras disposiciones. Aplicable a todos los productores de más de 200 llantas al año y a los que importen 50 o más automotores al año llantas hasta rin 22,5 pulgadas (vida+verde, s. f.).

Asimismo, desde 2012, la ANDI viene trabajando el Plan Posconsumo de Llantas mediante la Corporación Rueda Verde, entidad sin ánimo de lucro que ha desarrollado un sistema sostenible de recolección selectiva y gestión ambiental de llantas usadas, en busca de prevenir los posibles impactos al ambiente o a la salud según la regulación colombiana vigente (Pérez, 2014).

De acuerdo con la entidad, en la actualidad, su labor se adelanta en 20 de los 32 departamentos de Colombia, con la colocación de 177 puntos de recolección de llantas y un balance de más de 6500000 llantas recogidas en los últimos cuatro años, a los que, según informa la Corporación, se le ha dado una adecuada disposición final. La Corporación ha adelantado campañas de concientización sobre el abandono de llantas que incentiven a los ciudadanos a ser parte de la solución del problema (Dinero, 2017).

En Bogotá, hay entidades que buscan mejorar la recolección de llantas usadas, como la Secretaría de Ambiente, Aguas de Bogotá, la Unidad Administrativa Especial de Servicios Públicos (Uaesp), alcaldías locales, la ANDI y el Ejército Nacional atienden varios puntos afectados teniendo como fundamento la Resolución 1326/2017, de 6 de julio, por la cual se establecen los sistemas de recolección selectiva y gestión ambiental de las llantas usadas y se dictan otras disposiciones.

En una de las jornadas en la capital del país, fueron acometidos 27 puntos críticos en las localidades de Chapinero, Teusaquillo y Barrios Unidos, donde se retiraron de sus calles aproximadamente 2000 llantas (Dinero, 2017). 


\section{Clave del éxito en la gestión de residuos especiales como llantas}

$\mathrm{A}^{1}$ experto en gestión de residuos sólidos Antonis Mavropoulos $C_{\text {considera que la mejor manera de manejar los residuos especiales }}$ como las llantas es aplicar el principio de responsabilidad extendida del productor (REP), que señala que los productores de estos elementos también son responsables de su disposición final. Por ejemplo, en la Unión Europea, existen casos de éxito que involucran todas las industrias con tasas de reciclaje del $50 \%$ (El Tiempo, 2016b). También las campañas de concientización de la población en general sobre la importancia del reciclaje y la conservación ambiental.

\section{Problemática ambiental derivada de la inadecuada disposición de llantas}

E n contraposición a los beneficios que trajo la invención de la llanta a la humanidad y el promisorio futuro que según los expertos tiene el negocio actualmente en el país, se encuentra la problemática que trae consigo el desecho inadecuado de los neumáticos, luego de cumplido su ciclo de vida útil, y la mayor preocupación en ello es el destino de este material de desecho, que según se estima tiene un tiempo de degradación de cien años (vida+verde, 2011).

En 2015, salieron a la venta más de 5,3 millones de llantas en Colombia, que, una vez cumplido su ciclo de vida, pueden terminar en calles, avenidas y parques, y generar un problema ambiental y de salud pública para los ciudadanos (El Tiempo, 2016b). 
Se estima que en Colombia se desechan al año alrededor de 5300000 llantas usadas, que en peso equivalen a unas 100000 t. Del total de unidades generadas en el país, 2 millones se producen en Bogotá, casi una cuarta parte (el 37,7\%), de acuerdo con informe del Ministerio de Medio Ambiente y Desarrollo Sostenible, basado en el reporte del Programa Posconsumo de la ANDI (Gómez, 2016).

La inadecuada disposición de llantas usadas causa múltiples problemas ambientales y de salud pública; cuando se acumulan en bodegas, patios y veredas se convierten en casa de roedores e insectos y focos de contaminación. Otras son quemadas a cielo abierto tras lo cual afectan la calidad del aire y la mayoría son abandonadas junto a la basura sin ser estas un material biodegradable (Durán, 2016).

En consecuencia, del mal manejo de residuos, se pueden derivar dos grandes problemas (El Tiempo, 2016b): el primero es que muchos de estos desechos especiales contienen sustancias peligrosas que pueden causar grandes problemas al ambiente y la salud si se desechan en vertederos o sitios de disposición sin controles. Por ejemplo, en Indonesia y Filipinas, el impacto en la salud de este tipo de vertederos industriales peligrosos es mayor que el producido por la malaria. El segundo problema es que muchos de esos productos contienen importantes recursos que se perderán en caso de no ser recuperados (Tabla 2).

Tabla 2. Disposición final de llantas en Colombia

\begin{tabular}{|l|l|}
\hline Disposición final & Porcentaje \\
\hline Incineración y rellenos sanitarios & 71,9 \\
\hline Reencauche & 17,2 \\
\hline Uso artesanal & 6,2 \\
\hline Regrabado & 2,3 \\
\hline Otros usos & 2,3 \\
\hline
\end{tabular}

Fuente. Ministerio de Ambiente, Vivienda y Desarrollo Territorial, 2007. 
El peligro más significante de almacenar llantas es el riesgo potencial de incendios, que son muy difíciles de extinguir y generan una gran cantidad de humo. Por ejemplo, dos incendios ocurrieron en fechas cercanas en el barrio Fontibón de Bogotá, producto del manejo inadecuado de llantas y de la falta de control. El primero ocurrido el 4 de noviembre de 2014:

La combustión se originó inesperadamente en la bodega Grenner Group, que contenía 600 mil llantas, los organismos de socorro y del cuerpo de bomberos debieron evacuar y asegurar tres bodegas más donde había material carburante, debieron ser aisladas las empresas cercanas, y aunque según el reporte oficial no hubo personas lesionadas, el riesgo que corrieron fue muy grande. La empresa presentaba varios problemas el representante señor Luis Orlando Buitrago ya lo había denunciado. Entre ellos el incumplimiento de normas de seguridad, que evitaran una tragedia la ANDI había emprendido un proceso judicial para liberar el terreno y devolver el predio a su dueño. Según la denuncia de uno de los propietarios del lote, desde hace más de un año, no recibían nada por el lugar, la bodega se estaba deteriorando, los muros se estaban cayendo. (El Tiempo, 2014)

Tan solo mes y medio después un segundo incendio ocurre en la misma bodega de llantas que venía operando de forma ilegal desde 2013. El incendio puso en riesgo ambiental a tres localidades de Bogotá, tomo cuatro horas retirar escombros y llantas del lugar (El Tiempo, 2014).

A partir de ese momento la Secretaría Distrital de Ambiente decidió realizar una campaña para que las llantas usadas fueran llevadas a los 92 sitios de almacenamiento posibles distribuidos en toda la ciudad ( $E l$ Tiempo, 2014). 
Especialmente el incendio de noviembre prendió las alarmas de la ciudad, porque llegó a contaminar seis localidades y ocasionó problemas en la salud de los ciudadanos y evidenció las grandes dificultades que el manejo de estos residuos representaba para aquel momento, gracias a lo cual se fortalecieron las medidas de control. Fue considerada como la crisis ambiental de Bogotá más grave en los últimos diecisiete años, luego del colapso del relleno sanitario Doña Juana en 2007 (El Tiempo, 2014).

Como consecuencia, se citó a los involucrados del sector a una mesa nacional de llantas con el Ministerio de Medio Ambiente y Desarrollo Sostenible, el Ministerio de Transporte, la Autoridad Nacional de Licencias Ambientales (ANLA), la Secretaría Distrital de Ambiente, la ANDI y la Agencia Nacional de Infraestructura (ANI). La propuesta inicial del Distrito es modificar la resolución para que se definan las responsabilidades, los puntos y los procesos de disposición final y se incluya otro tipo de llantas en la cadena de gestión (Secretaría Distrital de Ambiente, s. f.).

El objetivo de la modificación radica en que el Gobierno Nacional adopte la política de utilizar gránulo de caucho triturado en las nuevas vías de cuarta generación, como ya se aplica en un $20 \%$ en las de la capital del país y utilizarlas en la generación energética. La Secretaría Distrital de Ambiente (s. f.) propone y está dispuesta a prestar toda la asesoría al Gobierno Nacional para que este adopte la política de reutilización del gránulo de llantas en las obras de infraestructura de cuarta generación, hecho que ya se adopta en las vías de Bogotá, donde se exige a los contratistas que el asfalto nuevo que se aplique en la ciudad incluya en un $20 \%$ gránulo triturado de llanta.

A partir de 2016, la política para la utilización del gránulo de caucho reciclado (GCR) en la construcción de vías se extendió a cobertura del territorio nacional y regional. Esto gracias a las decisiones tomadas por la Vicepresidencia de la República, el Ministerio de Medio Ambiente y 
Desarrollo Sostenible, el Instituto Nacional de Vías (Invías) y la ANI (Gómez, 2016).

El director operativo de Invías, Ernesto Correa, explicó: «Había que romper la inercia con esta innovación, y es parte de la política del instituto de usar tecnologías nuevas y limpias. En la medida en que se siga empleando se abrirá la puerta para su mayor utilización» (Gómez, 2016).

El presidente de la ANI, Luis Fernando Andrade, indicó: «El pavimento con caucho de llanta reciclada tiene la ventaja de que es más durable - toca repavimentar menos - y da mejor tracción para las llantas. Aunque la mezcla sea de mayor costo, resulta una mejor inversión a largo plazo, porque los pavimentos aguantan más» (Gómez, 2016).

Así mismo, señaló: «Estamos en un periodo de transición. Su uso será un proceso gradual, porque se necesita una gran infraestructura, instalaciones para almacenamiento de llantas, contar con buenas trituradoras y mezcladoras de asfalto que puedan utilizar la nueva tecnología. Aún no es obligatorio emplear la nueva tecnología, pero se podría pensar que en unos 5 años sí lo sea» (Gómez, 2016).

Por otro lado, el vicepresidente Germán Vargas Lleras añadió que, en la construcción de la vía, se incorpora el grano de las llantas, porque «tiene mucha durabilidad, lo que permitirá construir carreteras de buena calidad» (Gómez, 2016). Además, señaló: «En el sector de infraestructura se podrán absorber, en esta primera etapa, más de 500.000 llantas usadas» (Gómez, 2016).

La crisis ambiental originada por los incendios producto de la inadecuada disposición de las llantas usadas en Bogotá fue el detonante para que se tomaran medidas respecto del adecuado manejo de estos desechos y de la búsqueda de alternativas innovadoras, de ahí nació 
la idea de usarla para la pavimentación de vías y fue el comienzo del descubrimiento de un sinnúmero de usos y aplicaciones industriales.

\section{Plantas de reciclaje de polvo o granulado de caucho en Colombia}

Tn 2016, fue puesta en funcionamiento la cuarta y más grande Cplanta de reciclaje de llantas usadas de Colombia, luego de que el vicepresidente de la república y el sector de la infraestructura gubernamental decidieran ofrecer un incentivo en la calificación a los proponentes de licitaciones para la construcción o mantenimiento de vías, que incorporaran el polvo de caucho o granulado en la mezcla asfáltica para los pavimentos y lo utilicen en no menos del $10 \%$ de la longitud total que tenga la vía.

Esta planta trituradora montada por el Cerrejón e Indutrade Recycling en Albania -La Guajira- tuvo costos de construcción superiores a los COP 13000 millones, según Roberto Junguito, presidente del Cerrejón, cuenta con equipos de alta tecnología importados de Italia, con capacidad de procesar 2360 llantas al año usadas de equipos mineros, que podrán generar cerca de $2300 \mathrm{t}$ de acero y $5000 \mathrm{t}$ de polvo de caucho, y utilizar en las mezclas asfálticas; está en la capacidad de triturar desde las llantas gigantes de los equipos mineros, que tienen $4 \mathrm{~m}$ de diámetro y pesan 4 $\mathrm{t}$, hasta las que ruedan con los automóviles y procesan hasta $16 \mathrm{t}$ diarias del material, de acuerdo con lo expresado por Alejandro Aristizábal, representante de Indutrade. Las otras tres plantas trituradoras de llantas funcionan en Madrid (Cundinamarca), Yumbo (Valle del Cauca) y Río Claro (Antioquia) (El Tiempo, 2016). 
Sistema Verde, Cementos Argos y el sector de llantas de Fenalco inauguraron la segunda planta de trituración de caucho de llantas en el país, la de Madrid -Cundinamarca-; a su cargo se encuentra la planta de Río Claro.

Sistema Verde es una empresa que realiza la logística de recolección de llantas usadas, el procesamiento de sus componentes y el aprovechamiento de los materiales.

[...]Cementos Argos es nuestro aliado estratégico para el cierre del ciclo del residuo, mediante la sustitución de carbón por el material procesado por Sistema Verde, lo que mitiga los impactos por la extracción de combustibles fósiles y la emisión de gases de efecto invernadero $\left(\mathrm{CO}^{2}\right)$, ya que entre el 20 y el $40 \%$ de la llanta es caucho natural, es decir que proviene de un recurso natural renovable.

La planta de procesamiento de neumáticos usados en Madrid tiene la capacidad de triturar 400 llantas por hora, es decir, $6 \mathrm{t} / \mathrm{h}$, con lo que se podrá cumplir el acuerdo que realizaron la Alcaldía de Bogotá y Cementos Argos de hacer una adecuada disposición de unos 2,5 millones de llantas. Actualmente, en Colombia, se generan alrededor de 7 millones de llantas al año. Hoy en nuestra Planta Rioclaro estamos en la capacidad de coprocesar 20.000 toneladas al año, lo que equivale a cerca de 1.5 millones de llantas y además, con las inversiones que estamos realizando en Planta Cartagena, proyectamos que en el mediano plazo tendremos la capacidad de disponer en total hasta 65.000 toneladas por año, cerca de 4.5 millones de llantas. En definitiva, estaremos en la capacidad de aportar el $65 \%$ de la solución de esta problemática en Colombia, inicialmente en dos de las nueve plantas que tenemos en el país. (Fenalco, s. f.) 
«Entre las proyecciones realizadas por Sistema Verde, se encuentra la apertura de otras tres plantas. La siguiente será en Bucaramanga y las otras dos estarán ubicadas en el norte y suroccidente del país, con el fin de atender la demanda que va en crecimiento» (Fenalco, s. f.).

«La planta de trituración de Yumbo (Valle) denominada CORPAUL fue inaugurada luego de una inversión cercana a los $\$ 5.500$ millones y que, en un corto plazo, espera procesar 250.000 llantas de automóvil, camión y camioneta, para recuperar 1.600 toneladas grano de caucho y 250 de acero, al año» (San Vicente Fundación, 2014).

El proceso en la planta de Corpaul incluye el almacenamiento temporal de llantas, su reciclaje mediante un proceso de trituración, a lo largo del cual se recupera el $80 \%$ del caucho y el $95 \%$ del acero, insumos que se almacenan para su posterior comercialización como materia prima o para la elaboración de otros productos, tales como superficies para canchas deportivas para fútbol y pistas de atletismo, fabricación de tapetes, pisos, suelas para calzado, entre otros usos industriales.

\section{Proceso de producción del polvo o granulado de caucho}

Tos neumáticos se pueden clasificar en tres tipos según el desgaste Uque presenten:

- Reutilizables: presentan desgastes menores de 1,66 mm.

- Reencauchables: pueden ser reparados, ya que poseen una carcasa en óptimas condiciones.

- No reencauchables: rigurosamente dañados o deteriorados, están listos para que puedan ser reciclados, ya que cumplieron su vida útil. 
De esta forma, el reciclaje se realiza con la trituración de llantas usadas, ya que cuando pierden sus propiedades y no pueden ser reencauchadas no son reutilizables en el servicio automotor, pero permite reciclar y reutilizar los diferentes materiales que la componen, lo que tendrá beneficios para la ciudad donde se podrán ver bondades en la pavimentación y reparcheo de la malla vial con asfalto de mejor calidad, con lo que se verá una mejora y una mayor durabilidad con respecto al asfalto que se maneja en la actualidad.

El asfalto modificado con caucho granulado que incluye grano de caucho reciclado mejora notablemente las propiedades de las vías, ya que con la experiencia se ha demostrado que estas alcanzan a durar hasta un $50 \%$ más que las que se construyen con mezclas convencionales. Esta aplicación es usada mediante dos tipos de procesos: el proceso seco en el cual se usa el caucho reciclado como un agregado y el proceso húmedo en el cual se usa como un modificador de la mezcla.

En cuanto a los costos de usar estos tipos de mezclas, aumenta entre un 20 a un $40 \%$ dependiendo del tipo de proceso. El proceso húmedo es el más costoso de realizar con respecto a la inversión; sin embargo, teniendo en cuenta la relación costo-beneficio, se concluye que es mejor utilizar este tipo de mezcla, puesto que prolonga notablemente la vida útil de la vía. Dado que se ha demostrado que es más beneficioso y rentable usar las mezclas de asfalto modificado con caucho granulado reciclado, en la actualidad, se ha aumentado la utilización de estos tipos de mezclas, como consecuencia de reducción de costos en el momento de construir infraestructuras.

En lo referente a la granulometría del caucho triturado que se requiere para esta aplicación, es menor a 0,8 mm (Murcia y Romero, 2016) (Figura 1). 


\section{Métodos más utilizados en la recuperación de llantas}

Figura 1. Granulometría

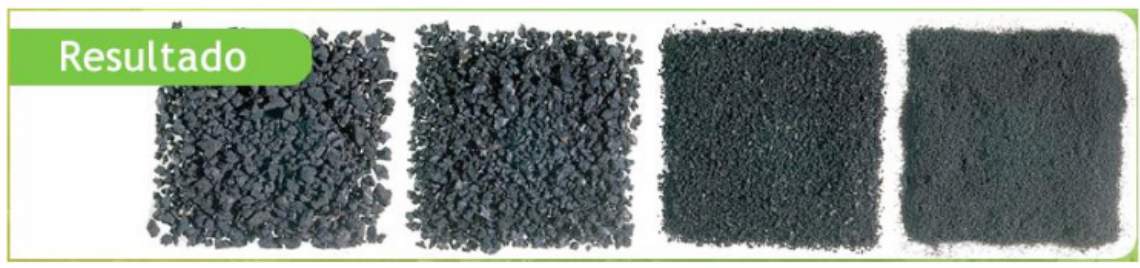

Fuente. Futuro ambiental, s.f.

- Termólisis: es una reacción química en la que un compuesto se separa en al menos otros dos cuando se somete a un aumento de temperatura. Se usa para producir neumáticos de nuevo.

- Incineración: es un proceso que se produce gracias a la combustión de diferentes materiales hasta que estos se conviertan en cenizas. Es altamente tóxico porque desprende gases y partículas cancerígenas.

- Pirólisis: es la descomposición térmica de un material en ausencia de oxígeno o cualquier otro reactante para producir gas parecido al propano, aceite industrial, coque y acero.

- Desvulcanización: proceso por el cual un material termoplástico se convierte en termostable, donde se mejora su dureza y elasticidad, sus aplicaciones son variadas.

- Trituración: proceso de reducción de tamaño de una materia sólida que implica solo una transformación física de la materia sin alterar su naturaleza. Existe la trituración criogénica, poco empleada, pues sus costos son altos y la calidad obtenida es baja; es un proceso complejo. Y la trituración mecánica, que no maneja químicos, ni calor, y reduce y tritura por un sistema de corte hasta disminuir el volumen del caucho. El acero es retirado por medio de una máquina que separa los alambres que están presentes en la llanta. Los componentes, como fibras, son separados en otros equipos. La ventaja que brinda este tipo de 
reciclaje es que produce nuevos productos lo que disminuye el daño al medio ambiente. La trituración mecánica es el proceso comúnmente utilizado en Colombia para la recuperación de llantas y es el menos contaminante (Figura 2).

Figura 2. Trituración mecánica

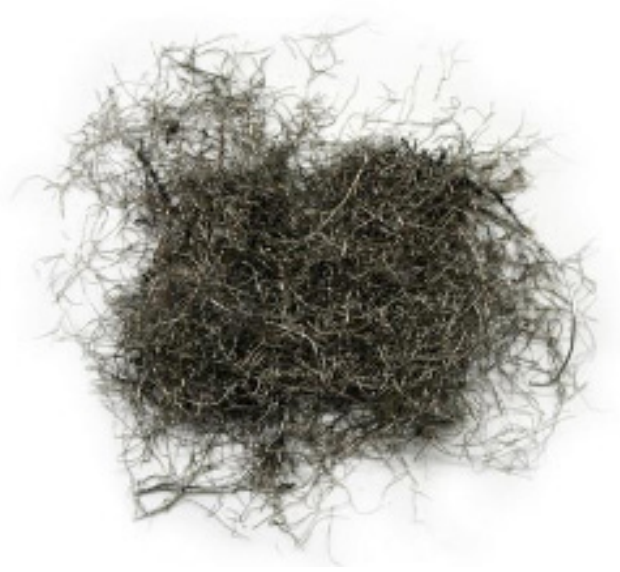

Fuente. Reciclar, s.f.

- Regeneración: se caracteriza por que rompe las cadenas que lo componen y así obtener materia prima, que, aunque tiene grandes diferencias con el material original, sirve para de nuevo vulcanizarse y fabricar caucho, usado para elaborar empaques para vehículos.

El proceso de reciclaje de llantas usadas y obtención de grano de caucho reciclado se lleva a cabo mediante trituración mecánica y abarca las siguientes fases:

- Recolección y clasificación de llantas: después de la ejecución de la estrategia para la recolección, se debe realizar una clasificación de acuerdo con el estado en que se encuentren.

- Limpieza: en esta fase, se realiza el lavado de las llantas con el fin de dejarlas limpias de cualquier agente contaminante. 
- Secado y almacenamiento: las llantas deben ser ubicadas en un lugar especial de almacenamiento que garantice que se encuentran libres de agua, jabón y que están totalmente secas.

- Trituradora primaria: esta máquina cuenta con unos cuchillos que realizan cortes, así se encarga de reducir el tamaño de la llanta a pedazos.

- Trituradora secundaria: los pedazos de llanta de gran tamaño deben pasar por una segunda trituradora que los reduce de 300 $\mathrm{mm}$ a $50 \mathrm{~mm}$.

- Granulador primario: esta máquina reduce el tamaño de los pedazos provenientes de la trituradora secundaria, la dimensión de los granos que se logra obtener es de $16 \mathrm{~mm}$.

- Separación de acero: en esta etapa, se separa el $99 \%$ del acero encontrado en las llantas por medio de un separador magnético que cuenta con una banda transportadora que se ocupa de conducir el metal hacia un cajón o contenedor - punto de recolección-.

- Granulado secundario: hay dos molinos de refinación, en los que una vez se han molido los granos caen en una banda transportadora, la cual conduce el material a otra criba rotativa que tiene tres parrillas de tres diferentes tamaños de orificios que van de $0,5 \mathrm{~mm}$ a $3 \mathrm{~mm}$.

- Pulverizado: en esta etapa, el caucho se encuentra ya libre de acero, material textil, nailon, por lo cual reduce su tamaño a 0,5 $\mathrm{mm}$ y es necesario que pase por un molino pulverizar de caucho que utiliza un proceso de embrague de discos rotatorios en sentidos adversos. Así se obtiene el polvo de caucho reciclado.

- Empacado y almacenamiento: el gránulo de caucho se deposita en una tolva, que contiene el gránulo seco, luego depositado en sacos de $50 \mathrm{~kg}$, ubicados en la zona de almacenamiento (Figura 3). 
Figura 3. Diagrama flujo de producción de grano de caucho reciclado

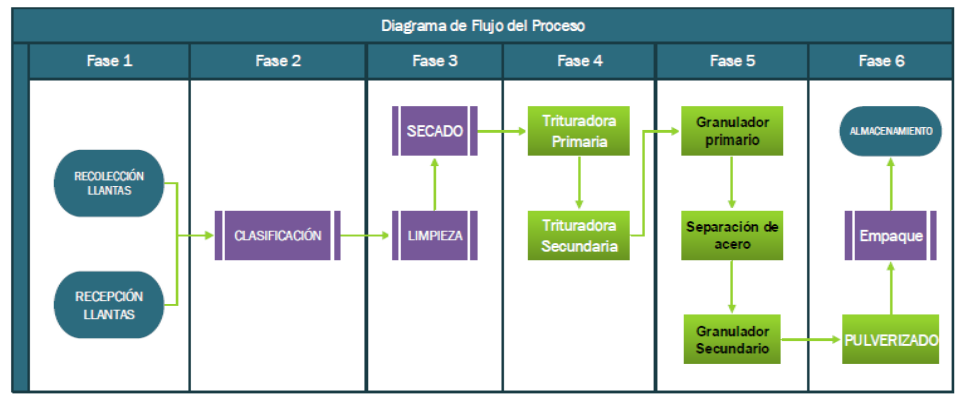

Fuente. Elaboración propia.

\title{
12. Costos que implica la producción de polvo o granulado de caucho por trituración mecánica
}

\begin{abstract}
libaba.com es un grupo empresarial fundado en 1999 que se perfila A como la plataforma de comercio electrónico más grande del mundo, reúne importantes importadores y exportadores de más de 240 países. De acuerdo con la información recopilada en este destacado portal de comercio electrónico, los precios por los que se puede adquirir una nueva máquina de reciclaje de neumáticos trituradora oscilan entre los USD 8000 (tipo 1) y los USD 180000 (tipo 2), es decir, unos COP 21000000 a COP 181000000 aproximadamente. Por ejemplo, la planta trituradora montada en 2016 por el Cerrejón e Indutrade Recycling en Albania tuvo costos de construcción superiores a los COP 13000 millones, produce $2300 \mathrm{t}$ de acero y $5000 \mathrm{t}$ de polvo de caucho. Las trituradoras más económicas (tipo 1) originarias de China tienen una capacidad aproximada de producción de 2 a $3 \mathrm{t} / \mathrm{h}$, mientras que las más costosas (tipo 2) alcanzan una producción de 10 a 15 t/ (Murcia y Romero, 2016).
\end{abstract}


El precio de una máquina trituradora de llantas usadas importada de la China capaz producir una capacidad de 2 a 4 ton/h es de alrededor de USD 60.000. Mientras que la planta de trituración de Yumbo (Valle) de CORPAUL fue inaugurada luego de una inversión cercana a los USD 1.929.148, para recuperar 1.600 toneladas grano de caucho y 250 de acero, al año. (Fenalco, s. f.)

Si un emprendedor quisiera inaugurar su propia planta, debería tener en consideración, además de los anteriores costos de la maquinaria principal, otros como compra o alquiler — inicial — de bodega de producción y almacenamiento, servicios públicos, impuestos, vehículo/s de transporte, mano de obra y personal administrativo, publicidad/ mercadeo, licencias, entre otros (Tabla 3).

Tabla 3. Inversión inicial estimada en pesos colombianos

\begin{tabular}{ll} 
Inversión & \\
\hline Activos Fijos & $\$ 190.000 .000$ \\
Inversión Diferida & $\$ 35.800 .000$ \\
Inversión de Capital de Trabajo & $\$ 66.200 .000$ \\
Total de Inversión & $\$ \mathbf{2 9 2 . 2 0 0 . 0 0 0}$
\end{tabular}

Fuente: (Garzon, 2012) Creación de una empresa dedicada al reciclaje de llantas a través de su trituración

Fuente. Garzón, 2012.

Se estima, entonces, que se debería contar con un mínimo de COP 21000000 a COP 30000000 para la compra de una máquina trituradora capaz de producir $1 \mathrm{t} / \mathrm{h}$, y para cubrir los demás costos de operación por otros entre COP 290000000 a COP 300000 000. Esto es la inversión inicial mínima que requiere suponiendo que inicialmente la empresa cuente con un mínimo de cinco colaboradores: operario de máquina, empacador, gerente, secretaria y vendedor, que representen una nómina de COP 10000000 mensuales, arrendamiento de bodega por COP 5000 0000, pago de servicios públicos por COP 2000000 y COP 6500000 , en otros varios. Además, es seguro que se necesitará realizar un préstamo por un valor aproximado de COP 120000000 a seis años, cuyo 
pago de cuotas mensualmente será de COP 2000000 aproximadamente, para cubrir sus costos iniciales y garantizar su supervivencia los primeros tres meses. En resumen, sus gastos y costos ascenderán entonces a COP 25500000 mensuales en promedio después de realizar la inversión inicial (Murcia y Mendoza, 2016).

Sin embargo, es aconsejable que inicialmente el emprendedor procure el trabajo bajo pedido, para disminuir sus costos de almacenaje y los riesgos a los que se verá enfrentado debido a los obstáculos que representa la comercialización, ya que, como se verá, solo una tercera parte de los volúmenes de producción que se puede lograr con la capacidad de la máquina se espera se vendan de forma eficaz, debido a los obstáculos existentes en el proceso de comercialización.

Con los datos que se presentan a continuación, se puede crear una tabla en la que se plasme la demanda proyectada en los primeros diez años del proyecto.

Precio de venta del kilogramo de caucho molido: COP 750, que son el resultado del costo del producto en el mercado, debido a que los costos logísticos son los más importantes en este proyecto, y es por esto por lo que estas empresas comercializadoras de llantas pagan un dinero de acuerdo con el mercado de COP 200/kg por concepto de recolección y la emisión del certificado de disposición de los materiales.

Para este caso de estudio, se asume que la recolección de estos materiales tiene un costo por la logística y que no se obtiene ningún ingreso por esta causa. Los costos por cada uno de los materiales son iguales a esos COP 200/kg para hacerlos llegar a la planta de producción, más un $50 \%$ de margen, con un adicional del $16 \%$ por concepto de impuestos (Tabla 4). 
Tabla 4. Costo logístico

Esto en resumen es $\$ 200$ por $\mathrm{kg}+$ IVA $16 \%=\$ 232$

$232 \$ / \mathrm{kg} * 1,5(50 \%$ mmargen $)=\$ 332$

Precio mercado $=\$ 750$ por $\mathrm{kg}$

De acuerdo al precio del mercado y para el beneficio del proyecto se considera $\$ 750$ por $\mathrm{kg}$ como el precio de venta.

Fuente. Elaboración propia.

Se aclara que el precio del mercado varía dependiendo del año, tanto impuestos como costos.

\section{Proceso de comercialización de los subproductos derivados de llantas usadas}

Tas llantas son el único producto dentro de los residuos especiales que $\checkmark$ puede ser reprocesado en su totalidad para obtener nuevas materias primas, pero se han encontrado obstáculos, particularmente en materia de comercialización, que no permiten cerrar con éxito su ciclo de vida útil (El Tiempo, 2016b).

Elmer Cardozo Guzmán, director de Rueda Verde, el más grande de los cinco programas que hay en el país para la recuperación de llantas usadas asegura:

Los gestores, encargados de transformar los neumáticos en subproductos como caucho, acero y fibras, solo llegan a comercializar entre el 50 y el 60 por ciento de las nuevas materias primas generadas. El país tiene capacidad para procesar 10 millones de llantas al año, pero se llega solo al 20 por ciento 
porque los subproductos obtenidos no están cumpliendo con su cuota de comercialización.

Esta dificultad contrasta con el éxito en los procesos de recuperación cuyas cifras son esperanzadoras, teniendo en cuenta que aún se está iniciando en el proceso de concientización de los usuarios. La meta de Rueda Verde para el 2016 es recoger dos millones de llantas en el país, medio millón menos de las desechadas por Bogotá cada año. Para cumplir con esa labor, la fundación dispone de 20 puntos en varios departamentos. (El Tiempo, 2016b)

La primera dificultad en el proceso de comercialización es la de buscar una infraestructura que se encargue del procesamiento de los neumáticos y lleve a cabo los procesos de trituración y separación. La segunda es la no creación de un mercado y cultura de uso de materiales reciclados, de caucho, cuyas propiedades y precios sean atractivos a los sectores industriales.

Los gestores se ven enfrentados a buscar las nuevas alternativas de salida para las llantas procesadas, entre ellas, el asfalto modificado para la construcción de vías.

No obstante, el ingeniero José Hernando Marín, jefe de la planta de reciclaje de Corpaúl, uno de los gestores que trabajan con Rueda Verde, señala que ese mercado aún no se ha explotado. Además, parte del material derivado del neumático para ese uso en Colombia ha sido importado de países como España y Trinidad y Tobago, restándole competitividad de precios al producto nacional. (El Tiempo, 2016b)

Además, dice que en otros usos como los granos de caucho de las canchas sintéticas se debe competir con productores informales que llegan a ofrecer precios inferiores hasta en 25 por ciento por kilo. Una 
tercera dificultad que encuentran los gestores de llantas de caucho es un mercado con mucha competencia, gran parte de ella informal, que vende sin IVA a menor precio sin importar la calidad. (Suarez, 2016).

\section{Algunos usos conocidos de los subproductos derivados de las llantas}

L

as llantas están compuestas por caucho $-80 \%$-, acero $-15 \%-\mathrm{y}$ sectores de la industria.

Con caucho, además del asfalto modificado, se puede utilizar granulado para canchas sintéticas, calzado, adoquines, como sustituto del aserrín y para reemplazar combustibles fósiles tradicionales, pues, según expertos consultados, llega a generar mayor energía que el carbón. (Suarez, 2016).

Con la aplicación de tecnologías fisicoquímicas también se pueden obtener otros subproductos, como aceites y combustibles tipo diésel, tras ser refinado.

Y hay una aplicación que incluso se puede lograr sin procesar la llanta: como materia prima de obras de ingeniería para el control de la erosión, en sitios lejanos donde llevar la llanta a una planta de recolección puede resultar complejo. (Suarez, 2016). 


\section{Pavimento hecho de llantas $y$ pavimento convencional}

Dara 2016, fue desarrollado por la Universidad Nacional de Colombia 1 sede Manizales, un modelo que permitió comparar el funcionamiento del asfalto elaborado a partir de llantas desechadas y el convencional, que fue probado en una vía de $160 \mathrm{~m}$ de longitud, que da acceso al Parque Tecnológico Ambiental de La Sabana Tecniamsa en Mosquera (Cundinamarca). La vía de estudio se dividió en siete tramos, tres de ellos con asfalto convencional y los otros cuatro construidos con una mezcla asfáltica con GRC (Motor, 2016).

El análisis incluyó siete procesos de inspección, fotografías, inventario y calificación de la condición del pavimento durante tres meses — de abril a julio de 2015-. Por esta vía, circularon 11780 vehículos de diferentes tamaños durante este periodo.

Los resultados demuestran que el asfalto GRC le ganó al convencional que presentó solo una falla por desprendimiento de agregados gruesos, mezcla de concreto, mientras en el convencional tres tramos mostraron este problema.

Presenta un desempeño igual o similar en la perdida de asfalto por abrasión casi en el mismo grado y de oxidación por el clima, un problema determinado meteorización.

Finalmente, el GRC resulto peor registrando algunos abultamientos y hundimientos en tres tramos mientras el convencional solo en uno. (Motor, 2016) 
Luego de seis meses ambos tramos se encontraban estado satisfactorio y bueno, con calificación un poco más alta para el GRC, lo cual indica que ambos materiales son idóneos en la construcción de vías.

En Colombia, el primero en utilizar este material reciclado en las vías fue el Instituto de Desarrollo Urbano (IDU), con pilotos en el 2003. Hoy es obligatorio aplicar la mezcla en un mínimo del 5 por ciento del total de la vía.

Estudios de la Universidad de los Andes sobre las vías del IDU hechas con el GCR han concluido que este incrementa la vida útil del pavimento y disminuye el ruido del tráfico al contacto con la carpeta asfáltica. (Motor, 2016)

En las vías nacionales, las primeras pruebas las hizo hace unos dos años el concesionario San Rafael en el corredor Girardot-IbaguéCajamarca. Más exactamente, aplicó la mezcla modificada en 600 metros de la variante Picaleña.

El gerente de la concesión San Rafael, Ezequiel Romero, dijo que las pruebas mostraron que «el pavimento es más durable y así necesita menos intervenciones». Agregó que el siguiente paso es invertir en una planta de asfalto moderna, con la tecnología que garantice la calidad de la mezcla requerida con el grano de la llanta reciclada.

Se calcula que para la producción de un metro cúbico de mezcla asfáltica con GCR se requieren aproximadamente 3 llantas y media.

Para la producción de una tonelada de grano de caucho reciclado se necesitarían 250 llantas.

Si se utiliza y aprovecha más este material usado en la infraestructura de carreteras, se garantizan buenas vías y se da, al mismo tiempo, una solución al grave problema ambiental que enfrenta el país (Gomez, 2016). 


\section{Algunos casos colombianos exitosos en el usado de granulado o polvo de caucho}

\subsection{Caso Gicomer SAS: Pisos de caucho tipo exportación.}

German y Federico Giraldo crearon GICOMER S.A.S y su marca Huella Urbana en 2010, ellos «convierten cauchos viejos en pisos nuevos». Luego de pasar por el proceso de separación y molienda, toman el grano de caucho reciclado, lo colorean y compactan para ofrecer una eco amigable opción de para recubrir suelos interiores y exteriores.

Gicomer es un emprendimiento colombiano que innovó en la recuperación de las llantas desechadas, para diseñar pisos con altos estándares de calidad tipo exportación para gimnasios, colegios y otras organizaciones. (Dinero, 2016).

Sus fundadores vieron en las llantas desechadas una oportunidad de negocio y el modo de influir positivamente en la problemática medioambiental, así es como de la experiencia de países europeos tomaron esta respuesta para producir pisos, a la que ven como «un negocio productivo, que genera empleo y es sostenible» Han registrado un crecimiento sostenido del $30 \%$ anual, la empresa busca ser fuente de empleo, e inspiración para que otros vean cómo se puede resolver un problema ambiental y ser rentable a la vez. (Dinero, 2016). 


\subsection{Caso Argos: Combustible para hornos de cemento.}

Cementos Argos utiliza la llanta picada como combustible alternativo en los hornos de cemento de la planta Rioclaro, que funciona en Antioquia. El vicepresidente de Innovación de la cementera, Camilo Restrepo, informó que están procesando mensualmente alrededor de 1.000 toneladas de llantas y se subirán a 1.500. La idea es llegar a 20.000 toneladas anuales en la planta de Rioclaro (Redaccion El Tiempo, 2016)

«De la mano del Sistema Verde — que hace la recolección de llantas usadas en Bogotá, Medellín y otras ciudades - se inició el co-procesamiento en la planta Argos de Rioclaro, como parte clave para la solución de la problemática de las llantas en el país».

La idea, expresó, es que este producto triturado sirva de combustible igualmente en la planta de Cartagena. Así la cementera tendría la capacidad de co-procesar unas 65.000 toneladas de este residuo al año. «Argos podría aportar el 60 por ciento de la solución a la disposición de las llantas. Usadas como combustible, no causan ninguna contaminación ambiental ni alteran la calidad del cemento, afirmó el directivo.» (Gomez E, 2016).

\subsection{Caso Universidad de los Andes: filtros de carbón activado.}

Juan Carlos Moreno Piraján, profesor de investigación en Solidos porosos y calorimetría de la Universidad de los Andes, tiene una propuesta: convertir las llantas en filtros de carbón activado para limpiar zonas contaminadas.

La propuesta de generar carbón activado es una de las más interesantes y olvidadas en el país. El carbón activado, también conocido como purificante o adsorbente universal, se parece mucho a una piedra 
pómez. Al ser un material poroso resulta útil para absorber contaminantes orgánicos e inorgánicos de los ríos y purificar el agua. Actualmente es utilizado para descontaminar sistemas gaseosos y líquidos, solventes y aceites, entre otros.

Hasta ahora, luego de varios años de investigación, el grupo de Moreno ha logrado obtener cinco tipos de carbón activado a partir de residuos de neumáticos - dado que tienen un alto contenido de carbono-, todos a un costo relativamente bajo. En pruebas de laboratorio han resultado útiles para tratar aguas contaminadas con diferentes metales, como plomo, mercurio, zinc y cromo, que se encuentran en algunos de nuestros ríos. En Colombia existen pequeñas industrias dedicadas a la fabricación de carbón activado (Duran, 2016).

El adecuado proceso de llantas usadas no solo tendría beneficios para el medioambiente, sino que podría convertirse en una alternativa económica para algunos empresarios. Por eso cree útil hacer una alianza entre diferentes entidades del Estado, la academia y la industria para profundizar la investigación en esta área. (Duran, 2016).

\subsection{Caso Cyclus: diseña productos a partir del reciclado de materiales urbanos}

Cyclus fue creada en Colombia en el año 2002, con una visión que pretende llevar un mensaje a través del diseño de productos, que tengan como principios básicos: la reutilización de materiales urbanos, el reciclaje de materias primas y la reducción de consumo de recursos y generación de desperdicios. (conciencia eco, 2010)

Cyclus empezó con dos personas y hoy cuenta con un equipo de más de 25 en Colombia, y muchas más alrededor del mundo en países como Reino Unido, Francia, España, Escandinava, Italia, Costa Rica, Canadá y Estados Unidos, entre otros. Además, posee talleres satélites entrenados 
en el manejo del material para expandir la producción. (concienciaeco. com, 2010)

El caucho de neumático es un material no biodegradable. La empresa toma neumáticos utilizados y luego de llevar a cabo un proceso limpio de recuperación - libre de químicos, para eliminar impurezas -, lo clasifica y corta de acuerdo con los moldes de cada accesorio, para finalmente ensamblarlo y coserlo. (concienciaeco.com, 2010)

Con productos de alta calidad, gran durabilidad, impermeabilidad y diseños modernos e innovadores, Cyclus se abre un nicho importante en el mundo, sumándose a los numerosos aportes en el ámbito ecológico, una forma de vida a la cual todas las personas, de una u otra forma, deberían entrar, y por ello fue galardonada con el Premio Nacional de Exportaciones 2009, en la modalidad de pequeña empresa. (concienciaeco.com, 2010)

La propuesta de esta empresa nacional que ofrece empleo a diversas personas vulnerables como hombres y mujeres cabeza de hogar de todas las edades, que viven en zonas alejadas de dónde está ubicada la fábrica que ayuda con la generación de empleo y de que tiene frente al mundo un negocio de calidad e impulso de materiales como el neumático reciclado factores de innovación y amigable con el medio ambiente. 


\section{Conclusiones}

a inversión inicial: el proyecto demanda una inversión inicial de $\checkmark$ mínimo COP 120 millones para comprar una máquina trituradora de calidad media y entrar en funcionamiento. Es posible ingresar al mercado como productor pequeño e ir fortaleciéndose poco a poco mientras crece la lista de clientes, aplicando una estrategia de comunicación eficiente al ser este un factor competitivo de gran importancia.

La maquinaria necesaria: existen diferentes precios para las trituradoras de llantas que van de acuerdo con su capacidad productiva. Es aconsejable empezar con una máquina de buena calidad, pero de capacidad pequeña, que puede costar unos COP 20 millones, en tanto que se planea cómo se hará frente a los obstáculos de falta de clientes inicialmente y el incentivo al uso de este subproducto en nuevas aplicaciones en distintas industrias.

El talento humano: basta un pequeño equipo de trabajo para la operación y administración de la planta de producción de gránulo de caucho, este deberá contar con la capacitación y formación idónea que se requiere. La empresa deberá considerar contar con un equipo de profesionales especializado en temas como investigación de mercados, desarrollo de nuevos productos y equipo de ventas adecuado si aspira a consolidarse en el mercado.

La producción: se puede adquirir maquinaria capaz de producir mínimo $1 \mathrm{t} / \mathrm{h}$, las empresas ya consolidadas producen alrededor de $6 \mathrm{t} / \mathrm{h}$, cuentan con aliados estratégicos y son grupos empresariales con capitales que les permiten altos volúmenes de producción. Un productor pequeño debe producir y vender como mínimo $24 \mathrm{t}$ al mes para superar su punto de equilibrio y tener un margen de utilidad del $9 \%$. 
La materia prima: la adquisición de la materia prima se encuentra garantizada para los fabricantes de gránulo de caucho reciclado, debido a la existencia a partir de 2012 en Colombia de regulaciones medioambientales, que obligan a las empresas productoras de llantas a crear un proyecto de reciclaje de estas que facilite su acopio y disposición. La materia prima es gratuita, al ser las llantas catalogadas como desperdicio y un problema para la población en general.

El transporte: el acopio de la llanta demanda de la empresa procesadora de llantas usadas disponer de medio de transporte para la recolección de las que han de constituir su materia prima. Así mismo, para la distribución de los productos terminados, el gránulo o polvo de caucho o los productos fabricados a partir de este, en función de su capacidad de producción.

La comercialización: las plantas de trituración existentes actualmente enfrentan dificultades en los procesos de comercialización del gránulo o polvo de caucho, los volúmenes de ventas son bajos, de un $20 \%$, frente a grandes volúmenes de materia prima producto de la recuperación exitosa de llantas. Estas empresas han enfrentado cinco principales obstáculos en el momento de incursionar en el negocio:

a. Búsqueda de la infraestructura adecuada para el reprocesamiento de las llantas, su trituración y separación. Esta siempre es una dificultad, pero hoy existe mayor facilidad para la adquisición de maquinaria, más productores de maquinaria, mayores posibilidades de financiamiento y mayor conocimiento de negocio que incentiva la oferta y demanda.

b. No creación de un mercado, ni cultura de reciclaje, y uso de materiales reciclados. Sin embargo, cada día nacen nuevas aplicaciones del gránulo de caucho y existe mayor conciencia respecto de la conservación ambiental y el reciclaje. 
c. Las nuevas aplicaciones del gránulo de caucho como el asfalto modificado constituyen un mercado que aún requieren ser explotado. Gran parte del material obtenido de los neumáticos para producir asfalto modificado es importado por Colombia desde países como España y Trinidad y Tobago, lo que resta competitividad a los precios del producto nacional.

d. Existen gran número de competidores informales para la producción del gránulo de caucho en la fabricación de pisos, que ofrecen precios muy inferiores hasta del $25 \%$ y venden sin IVA.

e. La cultura del consumidor es un problema, ya que este no es consciente de que las llantas no se pueden desechar como residuos ordinarios, sino que necesitan especial disposición. Las campañas de concientización ayudan y el interés de las nuevas generaciones por el reciclaje y la conservación son un aspecto esperanzador. No obstante, cabe resaltar que los obstáculos en la comercialización son susceptibles de ser superados y lo están siendo según demuestran los casos exitosos de los empresarios en esta industria en Colombia, estos sirven para inspirar y servir de modelo para el nacimiento de nuevos emprendimientos en torno a innovadoras aplicaciones del gránulo de caucho en la industria. Una estrategia para garantizar la cuota de ventas de la empresa productora de gránulo de caucho es hacer de este la materia prima para la fabricación de otro producto, por parte de la misma empresa, como ocurre con las empresas dedicadas a la fabricación de pisos a partir de gránulo de caucho reciclado como el caso de la empresa colombiana Gicomer.

Rentabilidad: se considera que la producción de gránulo o polvo de caucho es entonces un negocio rentable, del que se espera un pronto retorno de la inversión, debido a que existen muchos nuevos usos y aplicaciones por explorar, que abren la posibilidad del nacimiento de nuevos segmentos y nichos de mercado, donde es tarea del emprendedor innovar, investigar, mantenerse informado de los nuevos usos y anticiparse a las tendencias, 
construir campañas de concientización dirigidas a la población en general que faciliten su tarea. El margen de utilidad resulta atractivo aun en los primeros meses, cuando normalmente se espera iniciar a pérdida.

Nuevos productos, nuevos mercados: el granulado o polvo de caucho reciclado sirve como materia prima para un interminable número de usos y aplicaciones en diferentes industrias, entre ellas, además de la mezcla asfáltica o asfalto modificado, para construcción y recuperación de vías:

- Canchas sintéticas.

- Calzado, suelas.

- Adoquines.

- Sustituto del aserrín.

- Sustituto de combustibles fósiles tradicionales.

- Energía, mayor de la producida por el carbón.

- Con procesos adicionales, se obtienen aceites y combustibles tipo diésel.

- Para obras de ingeniería, impermeabilizaciones.

- Por su poder calórico, se usan en calderas y procesos industriales.

- Pistas atléticas.

- Canchas de tenis.

- Parques infantiles.

- Obras de arte.

- Aislamiento acústico y térmico.

- Muros antiexplosivos.

- Tejas.

- Aditivos para productos plásticos.

Contaminación y medio ambiente: las llantas usadas pueden dejar de ser unos desechos contaminantes para convertirse en una materia prima útil para la fabricación de aplicaciones amigables con el medio 
ambiente, de esta forma se reducen desechos contaminantes y a la vez se producen aliados ambientales como los filtros de carbón activado, útiles en la purificación del agua y descontaminación al absorber contaminantes orgánicos e inorgánicos en líquidos y gases.

El reciclaje de llantas en Colombia es una actividad poco explorada, pero con una alta proyección de desarrollo en nuestro país que se ve reflejada en la normativa existente. Este escenario representa dos grandes oportunidades de mercado: la primera para los operadores de sistemas de recolección y gestión ambiental de las llantas y la segunda para que los derivados directos, entre ellos, caucho, textil y acero, puedan ser utilizados en el proceso de valorización para la fabricación de productos como caucho para mezclas asfálticas, canchas sintéticas y como materia prima en la producción de materiales acústicos.

Si se considerara la producción de granulado de caucho como un proyecto de inversión, puede considerarse viable, al determinar que es sostenible y rentable, lo que la hace factible, o posible de realizarse y abrir oportunidades de explotación de negocios nuevos, que, con las tendencias de mercado a un cambio de mentalidad de apropiación hacia la naturaleza, estos proyectos hacen tangible tal oportunidad de negocio que se puede considerar con un alto porcentaje de realización tanto dentro como fuera del país. Lo anterior favorece al medio ambiente y genera empleo para la gente vulnerable como en Bogotá, que son las personas que viven del reciclaje y dependen de estas labores. 


\section{Referencias}

Clickmica (s. f.). La vulcanización del caucho. Recuperado de https://bit. ly/2oJrle3

Conciencia Eco (9 de octubre de 2010). CYCLUS, una empresa colombiana que diseña productos a partir del reciclado de materiales urbanos. Recuperado de https://bit.ly/2OdXbwl

Dinero (27 de abril de 2017). El promisorio futuro del negocio de las llantas en Colombia. Recuperado de https://bit.ly/2CTBPjD

Dinero (9 de octubre de 2017). Para las llantas usadas si hay vida después de la muerte. Recuperado de https://bit.ly/2YCE1C7

Durán, M. A. (17 de febrero de 2016). Llantas, de enemigo a aliado ambiental. El Espectador. Recuperado de https://bit.ly/2Eq81d9

El Comercio (14 de septiembre de 2012,). Historia de la llanta. Recuperado de https://bit.ly/2w3Z1Fz

El Tiempo (4 de noviembre de 2014). Bomberos dice que controló incendio en depósito de llantas de Fontibón. Recuperado de https://bit.ly/2Q6Zf85

El Tiempo (24 de julio de 2016a). Inauguran planta para reciclar llantas usadas que se usarán en vías. Recuperado de https://bit.ly/2Q6OCSv

El Tiempo (24 de octubre de 2016b). El reciclaje de llantas, un mercado que todavía falta por explorar. Recuperado de https://bit.ly/2VwN85c

Fenalco (s. f.). 400 llantas por hora triturará la nueva Planta de Procesamiento de Llantas en Desuso de Madrid, Cundinamarca. Recuperado de https:// bit.ly/2JQ5awW

Gómez, L. (17 de enero de 2016). Comienza era de vías que se harán con llantas usadas. Recuperado de https://bit.ly/2Q5Jxdo

Ministerio de Medio Ambiente y Desarrollo Sostenible (2017). Llantas usadas. Recuperado de https://bit.ly/2Jn2aZL 
Motor (27 de octubre2016). Pavimento hecho con llantas es igual al convencional. Recuperado de https://bit.ly/2WMvRqj

Murcia Correa, J. C. y Romero Mendoza, A. R. (2016). Diseño de un sistema primario en el proceso de trituración de llantas usadas desalambradas (Tesis de pregrado). Fundación Universidad de América, Bogotá, Colombia.

Pérez Díaz, V. (12 de noviembre de 2014). La Andi prevé recolectar este año 1 millón de llantas con Corporación Rueda Verde. La República. Recuperado de https://bit.ly/2HyuUv6

Resolución 1457de 2010 ( 29 de julio de 2010). Por la cual se establecen los sistemas de recolección selectiva y gestión ambiental de llantas usadas y se adoptan otras disposiciones. Diario Oficial, núm. 47786. Ministerio de Ambiente, Vivienda y Desarrollo Territorial.

Resolución 1326 de 2017. (6 de julio de 2017). Por la cual se establecen los sistemas de recolección selectiva y gestión ambiental de las llantas usadas y se dictan otras disposiciones. Diario Oficial, núm. 50287. Ministerio de Ambiente, Vivienda y Desarrollo Territorial.

San Vicente Fundación (2014). CORPAUL inaugura Planta de Reciclaje y Aprovechamiento de Llantas Usadas. Recuperado de https://bit. ly/2LKgldb

Secretaría Distrital de Ambiente (s. f.). Aspectos ambientales. Recuperado de http://ambientebogota.gov.co/de/aspectos-ambientales

Secretaría Distrital de Ambiente (s. f.). Primera mesa nacional de llantas busca redefinir programa de posconsumo. Recuperado de https://bit. ly/2v36QLo

Sierra, G. P. (2011). La fiebre del caucho en Colombia. Credencial Historia, 262. Recuperado de https://bit.ly/2YB6JmN

vida+verde (s. f.). Proyecto une a 52 empresas colombianas para reciclar adecuadamente las llantas usadas. Recuperado de https://bit.ly/2Jq37ka 